\title{
A CORREÇÃO COMO PROCESSO AVALIATIVO: DIFERENTES PERCEPÇÕES EM DIÁLOGO
}

SIMONE ARAUJO MOREIRA MARY RANGEL

\section{RESUMO}

A principal finalidade desta pesquisa é problematizar as percepções que professores e alunos têm dos objetivos da prática da correção dos exercícios nos cadernos de alunos do ensino fundamental I. Partiu-se, para isso, de um quadro teórico que conciliou estudos nos campos da didática e da avaliação, no intuito de compreender as relações entre os feedbacks $e$ as regulações das aprendizagens dos alunos. Por esse viés, foi relevante, também, refletir sobre a articulação entre os saberes repetidos e os saberes construídos pelos professores. Para além de apresentar formas e concepções de origens empíricas, essas questões foram problematizadas como práticas que reclamam revisão teórica e análises mais apuradas. Trata-se, portanto, de uma investigação que permite interpretar, compreender, questionar e sugerir novos caminhos para uma prática da correção a serviço da avaliação formativa.

PALAVRAS-CHAVE AVALIAÇÃO DA APRENDIZAGEM • AVALIAÇÃO FORMATIVA - PROCESSO DE ENSINO-APRENDIZAGEM • DIDÁTICA. 


\section{RESUMEN}

La principal finalidad de esta investigación es problematizar las percepciones que profesores y alumnos tienen de los objetivos de la práctica de la corrección de los ejercicios en los cuadernos de alumnos de la educación básica I. Por lo tanto, se partió de un cuadro teórico que concilió estudios en los campos de la didáctica y de la evaluación con el propósito de comprender las relaciones entre los feedbacks y las regulaciones de los aprendizajes de los alumnos. Desde este ángulo también fue relevante reflexionar sobre la articulación entre los saberes repetidos y los saberes construidos por los profesores. Más allá de presentar formas y concepciones de orígenes empíricos, dichas cuestiones fueron problematizadas como prácticas que demandan revisión teórica y análisis más profundos. Así, se trata de una investigación que permite interpretar, comprender, cuestionar y sugerir nuevos caminos para una práctica de la corrección al servicio de la evaluación formativa.

PALABRAS CLAVE EVALUACIÓN DEL APRENDIZAJE • EVALUACIÓN FORMATIVA - PROCESO DE ENSEÑANZA-APRENDIZAJE • DIDÁCTICA.

\section{ABSTRACT}

The main purpose of this study is to problematize the perceptions that teachers and students have of the objectives of the practice of correcting exercises in students' notebooks in elementary school I. It is, therefore, based on a theoretical framework that reconciles studies in the fields of instruction and evaluation, in order to understand the relationships between feedback and regulation of students' learning. From this perspective, it was also relevant to reflect on the articulation between knowledge repeated or constructed by teachers. In addition to presenting forms and conceptions of empirical origins, these issues were problematized as practices that demand more thorough theoretical revision and analysis. Therefore, this deals with an investigation that allows interpretation, understanding, questioning and suggestion of new paths to a practice of correction for the purpose of formative evaluation.

KEYWORDS LEARNING EVALUATION - FORMATIVE EVALUATION • TEACHING-LEARNING PROCESS • DIDATICS. 


\section{A PRÁtICA DA CORREÇÃO COMO PROCESSO AVALIATIVO}

A prática da correção de exercícios nos cadernos de alunos do ensino fundamental I precisa ser discutida como função formativa no processo de avaliação. Para tanto, é oportuno se reportar, inicialmente, a um dos conceitos que, sustentado por Perrenoud (1999, p. 78), define a avaliação formativa como "toda avaliação que ajuda o aluno a aprender e a se desenvolver, ou melhor, que participa de regulação das aprendizagens e do desenvolvimento no sentido de um projeto educativo".

Ao aplicar o conceito à prática, Afonso (2009) observa que tal processo formativo pode ser realizado por meio de uma pluralidade de métodos e técnicas, os quais vão desde os recursos que auxiliam o acompanhamento do professor e os registros do progresso do aluno até as diferentes formas de interação pedagógica. Também contribuindo com esse debate, Fernandes (2006, p. 29) afirma que:

A construção de uma teoria de avaliação formativa deve assentar numa sólida base de investigação empírica que nos ajude a compreender questões tais como as relações 
entre as aprendizagens dos alunos e as tarefas que thes são propostas, as relações entre o feedback e a regulação das aprendizagens por parte dos alunos ou as relações entre os conhecimentos científicos e pedagógicos dos professores e as formas como organizam e interagem a avaliação nos processos de ensino e aprendizagem.

Partindo desses princípios, é possível afirmar que a prática da correção pode e deve ser utilizada como processo avaliativo na função formativa, pois contempla as dimensões descritas pelos autores citados nos seguintes aspectos:

- É um processo que possibilita obter informações sobre as aprendizagens dos alunos.

Por intermédio das correções, pode-se observar a natureza dos erros dos alunos como elemento que oferece pistas sobre as formas de pensar as questões propostas nas atividades. Como os alunos escrevem, o que indagam, o que respondem e como desenvolvem o pensamento são elementos essenciais para o professor conhecer melhor o aluno. Numa perspectiva construtivista do conhecimento, esses elementos situam os alunos nos diferentes estágios das estruturas operatórias (PIAGET, 2010), os quais podem ser ignorados ou favorecidos pela escola, dependendo dos métodos e das técnicas utilizadas.

- É um processo que possibilita planejar a ação dos professores na previsão das atividades (o que vou ensinar) e na regulação das aprendizagens (como vou ensinar).

A partir do conhecimento das aprendizagens dos alunos nas atividades propostas, pode-se trabalhar sobre os níveis de dificuldade e de facilidade nas elaborações das tarefas, as quais devem promover a integração dos processos de ensino, de aprendizagem e de avaliação. A regulação, quando bem conduzida, é capaz de favorecer situações de

[...] equilíbrio por autorregulações que permitem remediar as incoerências momentâneas, resolver problemas e superar crises ou desequilíbrios, por uma ação constante. (PIAGET, 2010, p. 37) 
- É um processo que contribui com a interação professor-aluno, com especial destaque aos níveis do feedback e aos estudos de Vigotski (2007) sobre as zonas de desenvolvimento.

Nessa dimensão, a prática da correção extrapola a estreita análise da dicotomia erro/acerto. Portanto, a qualidade do feedback precisa estar comprometida com a conscientização dos alunos acerca das suas diferenças entre o estado real e o que pretendem alcançar. É a partir desse entendimento que os alunos podem trabalhar para reduzir ou eliminar tais diferenças. Paralelo a isso, é nas interações professor-aluno e aluno-aluno que cresce a possibilidade de avanços significativos ocorrerem. Durante uma correção em sala de aula do ensino fundamental I, a qualidade da interação entre esses sujeitos é de extrema relevância para a ocorrência de tais avanços.

No trajeto da pesquisa em campo, buscaram-se, com base na prática da correção, elementos consistentes de uma ação interativa que permaneça ao longo de todo o processo de aprendizagem. Dessa forma, consolida-se o entendimento da correção com propósito de avaliação formativa, pois, segundo Perrenoud (1999, p. 111), ela desempenha um papel de "dispositivo que favorece uma regulação contínua das aprendizagens”. Trata-se de uma modalidade que propõe, portanto, uma otimização entre a avaliação e as intervenções.

É necessário pensar as intervenções e os feedbacks não como forma de elevar os índices de respostas certas, mas sim no sentido de promover possibilidades de avanços do conhecimento. Durante as correções, os professores têm a oportunidade de interagir com os dados que os alunos apresentam - orais, comportamentais ou escritos -, utilizando diversos recursos. Nesse aspecto, podem ser questionadas as marcas nos cadernos feitas pelos professores, sem que tenha havido uma interação com os alunos que pudesse levá-los à compreensão do que realizaram e de como avançar.

Além disso, no tocante ao feedback, é oportuno considerar os estudos de Vigotski (2004, p. 143) sobre a educação dos sentimentos, quando ele afirma que "nenhuma forma 
de comportamento é tão forte quanto aquela ligada a uma emoção". Essa observação provoca uma reflexão sobre os impactos da prática da correção nas aprendizagens dos alunos.

Que aprendizagens são essas? As que valorizam o certo ou o errado? As que emergem das codificações dos professores por meio de marcas e comentários nem sempre compreendidos nos cadernos? As que se associam a relações de poder que se estabelecem entre quem corrige e quem "é corrigido"? As que se associam à vergonha, à dependência e ao medo? Ou, ao contrário, as que se associam à confiança, à autonomia e à elevação da autoestima?

Para exercer a prática da correção de exercícios dos cadernos dos alunos numa perspectiva formativa e construtivista, métodos e técnicas deveriam estar compatíveis com essa finalidade, garantindo o propósito de que os alunos compreendessem e adotassem, por exemplo, parâmetros de normas cultas de redação, a partir das correções, bem como parâmetros de raciocínios, conceitos e processos adequados em cada área do conhecimento.

Por fim, entende-se que as entrelinhas dessa prática, e suas complexidades, são repletas de fatores subjetivos. As formas como os professores procedem e como os alunos percebem a correção podem produzir, caso não se encaminhem com propósito formativo de contribuições às aprendizagens, uma noção equivocada sobre os objetivos que a caracterizam, já que se trata de um processo avaliativo.

\section{DIFERENTES PERCEPÇÕES EM DIÁLOGO}

Para problematizar as percepções que professoras e alunos tinham dos objetivos da prática da correção dos exercícios de cadernos do ensino fundamental I, realizou-se a pesquisa em uma escola da rede municipal de Niterói-RJ. Durante o $2^{\circ}$ semestre de 2012, quatro professoras e 106 alunos do $2^{\circ}$ ao $5^{\circ}$ ano colaboraram com o projeto disponibilizando materiais, participando de entrevistas e preenchendo o questionário proposto.

As primeiras análises foram desenvolvidas a partir da compilação das respostas fornecidas pelos alunos ao ques- 
tionário, o que não foi uma tarefa simples. Assim, além das respostas ao questionário, foram consideradas observações feitas durante a pesquisa. Ao término de cada aplicação, conversou-se com as professoras e, conjuntamente, foram lidas e comentadas as respostas dos alunos.

Apresentam-se os dados em termos da frequência, absoluta e relativa (\%), de cada alternativa de resposta, segundo a pergunta do questionário e ano que o aluno está cursando no ensino fundamental I, nas tabelas 1,2 , 3 e 4 ( $1^{\text {a }}$ parte), e, em seguida, tece-se a análise ( $2^{\mathrm{a}}$ parte), trazendo ao corpo do texto os referenciais teóricos nos quais buscou-se apoio. Ainda na $2^{\text {a }}$ parte, promoveu-se um cruzamento entre os dados obtidos nos questionários e alguns outros obtidos por meio das entrevistas com as professoras.

Para detalhamento, assim será apresentado tal material: $1^{a}$ parte: Tratamento dos dados

Trata-se de um esforço de sistematização metodológica. Procurou-se, aqui, tecer uma categorização com base no objetivo geral de analisar as percepções que professoras e alunos têm sobre os objetivos da correção de exercícios realizados nos cadernos durante as aulas de quatro turmas do ensino fundamental I do segundo ao quinto ano.

\section{$2^{\mathrm{a}}$ parte: Análise}

As respostas à primeira e segunda perguntas do questionário correspondem à percepção dos alunos sobre o objeto de estudo. Nesse ponto, foram confrontadas diferentes percepções - as dos alunos e as das professoras - e socializadas as respostas com as professoras, a fim de se fazer uma reflexão conjunta sobre os dados.

As respostas fornecidas para as perguntas 3, 4 e 5 evocaram reflexões acerca da questão central da pesquisa: a percepção das professoras e dos alunos. Para fazer tal análise, confrontaram-se novamente as diferentes percepções e foram trazidas das entrevistas com as professoras as respostas para a questão: A professora percebe a correção como prática padronizada ou como prática que possibilita regular as aprendizagens dos ahunos?

Cabe ressaltar que as respostas à quarta pergunta não deram origem a uma distribuição de frequência na $1^{\mathrm{a}}$ parte. 
Acerca dela, após conversa com as professoras sobre as respostas dos alunos ao questionário, foi feita análise diretamente baseada no entendimento dos objetivos da prática da correção dos exercícios nos cadernos.

TABELA 1 - Distribuição das respostas fornecidas pelos alunos para a pergunta: "Quem corrige os seus deveres?"

\begin{tabular}{|c|c|c|c|c|c|c|}
\hline \multirow{3}{*}{$\begin{array}{l}\text { QUEM CORRIGE OS SEUS } \\
\text { DEVERES? } \\
\text { Total }\end{array}$} & \multicolumn{4}{|c|}{ ANO DO ENSINO FUNDAMENTAL I } & \multirow{2}{*}{\multicolumn{2}{|c|}{ TOTAL }} \\
\hline & \multirow{2}{*}{$\frac{2 \circ \text { ANO }}{21}$} & \multirow{2}{*}{$\frac{3 \circ \text { ANO }}{22}$} & \multirow{2}{*}{$\begin{array}{c}4^{\circ} \text { ANO } \\
22\end{array}$} & \multirow{2}{*}{$\frac{5 \circ \text { ANO }}{25}$} & & \\
\hline & & & & & 90 & $100 \%$ \\
\hline O próprio aluno & 3 & 0 & 2 & 6 & 11 & $12 \%$ \\
\hline Aluno e professora/pais/familiares & 12 & 2 & 2 & 4 & 20 & $22 \%$ \\
\hline A professora & 6 & 20 & 18 & 15 & 59 & $66 \%$ \\
\hline
\end{tabular}

Fonte: Moreira (2012).

A resposta à primeira pergunta, "Quem corrige os seus deveres?”, contrariando as expectativas das professoras, já evidenciou a distância entre a percepção da professora e a do aluno (Tabela 1). A expectativa era a de que os alunos se mostrassem autônomos, sujeitos nas correções, apropriando-se do ato de corrigir como um momento de ensino e de aprendizagem. Porém, em vez de trazerem essas informações na esperada resposta "Eu", os alunos delegaram primeiramente à professora essa tarefa e, depois, à mãe, ao pai e aos irmãos mais velhos. Não obstante tenham se incluído no processo, os alunos sinalizaram o reconhecimento de um saber que, superior ao deles, é capaz de, seguramente, regular suas aprendizagens e apontar o certo e o errado.

Nesse sentido, tomou-se como referência o artigo de Veiga (2011) que trata de fundamentos teóricos da demonstração didática. A autora faz considerações sobre os processos de ensino que ocorrem em laboratório e, para tanto, utiliza estudos sobre o enfoque do papel da didática a partir dos pressupostos da pedagogia histórico-crítica. Ela situa, então, o professor "como responsável pela escolha da forma de condução do processo de ensino" (VEIGA, 2011, p. 140), acrescentando que: 
Cabe ao professor questionar não só "o quê" do conteúdo a ser ensinado, mas também "o como" se pretende ensinar esse conteúdo. E mais ainda: questionar "o quê" e "como" em função de quais interesses. Enfim, questionar sua prática pedagógica em função dos objetivos pedagógicos e sociais aos quais ele serve (VEIGA, 1989, p. 70).

Perguntar "Quem corrige os seus deveres?" aos alunos provocou uma primeira reflexão sobre a relação entre a prática pedagógica e os objetivos traçados pelas professoras. A análise de conteúdo das respostas dadas ao questionário levou a entender a questão a partir de duas vertentes de respostas com as seguintes frequências: $12 \%$ dos alunos se situam no processo de correção como sujeitos, chamando para si a responsabilidade de lidar com o próprio material e manter o nível de atenção e participação durante a atividade, enquanto $88 \%$ não se identificam nesse processo, delegando ao outro a responsabilidade e a competência para isso.

TABELA 2 - Distribuição das respostas fornecidas pelos alunos para a pergunta: "Você entende quando a correção é feita?"

\begin{tabular}{|c|c|c|c|c|c|c|}
\hline \multirow{2}{*}{$\begin{array}{l}\text { VOCÊ ENTENDE } \\
\text { QUANDO A CORREÇÃO } \\
\text { É FEITA? }\end{array}$} & \multicolumn{4}{|c|}{ ANO DO ENSINO FUNDAMENTAL I } & \multirow{2}{*}{\multicolumn{2}{|c|}{ TOTAL }} \\
\hline & $2 \circ$ ANO & $3 \div$ ANO & $4 \stackrel{\circ}{A N O}$ & $5 \div$ ANO & & \\
\hline Total & 21 & 22 & 22 & 25 & 90 & $100 \%$ \\
\hline Sim & 18 & 19 & 18 & 16 & 71 & $79 \%$ \\
\hline Não & 0 & 0 & 0 & 1 & 1 & $1 \%$ \\
\hline Às vezes & 3 & 3 & 4 & 8 & 18 & $20 \%$ \\
\hline
\end{tabular}

Fonte: Moreira (2012).

Para analisar as respostas fornecidas à segunda pergunta, foram cruzados os seguintes dados:

- respostas escritas pelos alunos;

- observação do momento da correção conduzida pela professora perante toda a turma, com atenção ao "como" era realizada; 
- análise de conteúdo das marcas no caderno feitas pelos alunos, os quais explicaram os significados do que faziam;

- análise de conteúdo das marcas no caderno feitas pelas professoras, procurando ouvir dos alunos o significado que atribuíam a esse tipo de correção.

Partindo dos dados numéricos, verifica-se que $79 \%$ dos alunos situam-se na categoria dos que entendem quando a correção é feita e $21 \%$ na dos que não entendem (Tabela 2). Procurou-se, então, compreender, nessa distribuição, o que se descreve a seguir.

Após um momento de correção dirigida pelas professoras, aplicou-se o questionário. Enquanto a correção era feita, foi perguntado aos alunos o que estavam marcando em seus cadernos. Eles explicavam com os seguintes comentários: "Estou marcando que errei", "Estou dando o certo" e "Minha resposta tava incompleta". Ou seja, havia uma relação entre o que estava sendo feito pela professora (ou pelos colegas que iam ao quadro) e pela maioria dos alunos que acompanhavam o processo seguindo, nos cadernos, as questões abordadas.

No entanto, foi solicitada às professoras a permissão para analisar os cadernos dos alunos que não fossem aqueles que estavam em uso na correção, mas sim os que seriam da atividade seguinte e que estavam em posse delas, no armário. Assim foi feito.

Analisou-se o número de cadernos correspondente ao total de alunos por turma (106 cadernos) e, após entregá-los para que os alunos copiassem a próxima tarefa, procurou-se obter informações deles sobre as marcas feitas pelas professoras. Constatou-se que poucos alunos compreendiam na íntegra os significados dessas marcas, que consistiam em interrogações, dois traços embaixo de uma letra, risco em cima de frases e reticências seguidas de interrogações. Não ocorria o mesmo, porém, com marcas como "certo", "errado" e "meio certo", além dos comentários escritos, do tipo "Melhore a letra!", "Parabéns!", "Muito bom!” ou "Precisa caprichar mais!". Essas marcas eram entendidas pelos alunos. 
1 O termo "atividade" é utilizado aqui com o significado de "ações dos alunos orientadas pelos procedimentos, no sentido de (re)construírem o caminho (o método da aprendizagem) do conhecimento" (RANGEL, 2005, p. 13)
No primeiro contato com as quatro professoras, foi unânime a reação delas diante do tema da pesquisa. Disseram frases do tipo "Th... eu não faço aquela correção que todos estão acostumados, não!", ou “Ah, mas eu não levo mais caderno para casa... tenho problema de coluna", ou ainda "Olha, com as condições que trabalho aqui, não dá para fazer aquela correção, não!”. Nesses comentários, pode-se entender que as professoras estavam se referindo à correção que fazem somente dos materiais dos alunos, sem que haja interação com eles. E, embora assim afirmassem, foi possível observar que as duas técnicas eram utilizadas: correção dirigida pela professora com a participação dos alunos e correção dos cadernos e dos exercícios realizados por eles, sem nenhum tipo de interação.

Segundo Abrahão (2008), em pesquisas que investem nos procedimentos que os professores utilizam para verificar a produção do estudante, constatam-se muitas dificuldades. A autora acrescenta ainda que "É muito forte o interesse dos professores em ter em mãos algo concreto para que possam avaliar e emitir juízo acerca da produção do estudante" (ABRAHÃO, 2008, p. 247).

O grande problema se dá nesse aspecto, uma vez que os estudantes manifestam suas aprendizagens em formas e tempos diferenciados. Se, por parte da professora, não houver um cruzamento entre a atividade ${ }^{1}$ da correção durante as aulas e a observação direta dos cadernos, essa emissão de juízo acerca do processo de aprendizagem do aluno, por conseguinte, poderá ficar parcialmente comprometida. Avaliar uma só vertente não garante uma possibilidade de intervenção significativa na construção do conhecimento do aluno.

É importante ressaltar também que, observando os procedimentos utilizados pelas professoras, foram constatadas diferenças pontuais entre eles, as quais não se baseavam em progressão de dificuldades e não seguiam uma lógica sequencial por ano escolar - apesar de algumas professoras afirmarem que assim conduziam porque era compatível com alunos daquela idade. Por exemplo, observou-se que os alunos do $2^{\circ}$ ano ajudavam a "corrigir" as tarefas dos colegas de sala, enquanto no $4^{\circ}$ ano isso já não era permitido. O mesmo acontecia com os 
alunos do $5^{\circ}$ ano, que, como os do $2^{\circ}$, trocavam material uns com os outros. $\mathrm{O} 3^{\circ}$ ano investia mais em um movimento individual, em que cada um cuidava do seu material.

Foi possível perceber nisso uma certa confusão de ordem de estruturação lógica e sociopsicológica (RANGEL, 2005), que pode ser atribuída, também, ao fato de as professoras não discutirem em reuniões os procedimentos de correção que adotavam. Elas instituíam, por si sós, o que consideravam apropriado para aquele ano escolar; "combinavam" com seus alunos e aplicavam.

Ao se analisarem, por fim, as respostas dos alunos à segunda pergunta, não é difícil verificar o princípio da interação como fator relevante à compreensão e à aprendizagem. $\mathrm{O}$ fato de os alunos poderem se posicionar, perguntar e ouvir as dúvidas dos colegas e as explicações das professoras traz contribuições significativas para esse processo.

TABELA 3 - Distribuição das respostas fornecidas pelos alunos para a pergunta: "Você acha importante corrigir o dever?"

\begin{tabular}{|c|c|c|c|c|c|c|}
\hline \multirow{2}{*}{$\begin{array}{l}\text { VOCÊ ACHA IMPORTANTE } \\
\text { CORRIGIR O DEVER? }\end{array}$} & \multicolumn{4}{|c|}{ ANO DO ENSINO FUNDAMENTAL I } & \multirow{2}{*}{\multicolumn{2}{|c|}{ TOTAL }} \\
\hline & $2 \circ \mathrm{ANO}$ & $3 \div$ ANO & $4 \stackrel{\circ}{A N O}$ & 5ANO & & \\
\hline Total & 21 & 22 & 22 & 25 & 90 & $100 \%$ \\
\hline Sim & 18 & 22 & 20 & 25 & 85 & $94 \%$ \\
\hline Não & 3 & 0 & 2 & 0 & 5 & $6 \%$ \\
\hline
\end{tabular}

Fonte: Moreira (2012).

No que concerne à terceira pergunta, alunos e professoras percebem a correção como uma estratégia didática de intervenção, ensino e aprendizagem. Todavia, convém destacar que, no questionário, a terceira pergunta é seguida de "Por quê?", sendo nessa extensão de resposta que foi localizada expressiva preocupação por parte dos alunos com a relação dicotômica entre os erros e os acertos (Tabela 3).

Segundo a maioria dos alunos, é importante saber se errou ou acertou. Nessa lógica, foram observados os seguintes desdobramentos, refletidos em suas reações: 
- se acertam, ficam felizes, com a autoestima elevada (a maioria);

- $\quad$ se erram, não gostam, pois demonstram não saber, e isto é ruim perante a turma e a professora (a maioria);

- se acertam ou erram, não se abalam, pois veem nesse processo possibilidades de aprender (a minoria).

A quarta pergunta (“Para o que serve a correção?") apresentou certa redundância com as respostas dadas ao "Por quê?”, da terceira questão. Por esse motivo, procurou-se refletir, juntamente com as professoras, sobre essas respostas, buscando compreender como percebiam os objetivos da prática da correção.

A partir dessas informações, foi possível entender que as professoras se valem dessa estratégia didática como forma de potencializar as seguintes funções:

- de diagnóstico, que propicie o reconhecimento dos potenciais e das dificuldades dos alunos;

- de regulação da aprendizagem, em determinados momentos, e de emancipação da aprendizagem, nos procedimentos que adotam, procurando incentivar a autonomia intelectual dos alunos;

- de formação, como possibilidade de promover intervenções que favoreçam avanços nas aprendizagens e na autonomia dos alunos.

Não foram feitas referências às modalidades da avaliação sobre o ensino por parte das professoras. Na função diagnóstica, por exemplo, a conversa girou em torno das aprendizagens dos alunos, sem que houvesse, no entanto, uma consideração sobre as relações que ocorrem entre "professores, alunos, conteúdo e contexto de aprendizagem" (RANGEL, 2005, p. 14). 
TABELA 4 - Distribuição das respostas fornecidas pelos alunos para a pergunta: "Depois que o dever do caderno é corrigido, ele serve para alguma coisa?"

\begin{tabular}{|c|c|c|c|c|c|c|}
\hline \multirow{2}{*}{$\begin{array}{l}\text { DEPOIS QUE O DEVER DO } \\
\text { CADERNO É CORRIGIDO, ELE } \\
\text { SERVE PARA ALGUMA COISA? }\end{array}$} & \multicolumn{4}{|c|}{ ANO DO ENSINO FUNDAMENTAL I } & \multirow{2}{*}{\multicolumn{2}{|c|}{ TOTAL }} \\
\hline & $2 \circ$ ANO & $3 \circ \mathrm{ANO}$ & $4 \div$ ANO & $5 \div \mathrm{ANO}$ & & \\
\hline Total & 21 & 22 & 22 & 25 & 90 & $100 \%$ \\
\hline Sim & 9 & 18 & 17 & 24 & 68 & $76 \%$ \\
\hline Não & 7 & 1 & 5 & 1 & 14 & $16 \%$ \\
\hline Não souberam responder & 5 & 3 & 0 & 0 & 8 & $9 \%$ \\
\hline
\end{tabular}

Fonte: Moreira (2012).

A partir dos dados obtidos com a quinta pergunta ("Depois que o dever do caderno é corrigido, ele serve para alguma coisa?"), é possível observar que $76 \%$ dos alunos respondentes afirmaram que o dever já corrigido no caderno serve para alguma coisa (Tabela 4). Porém, após essa pergunta, foi acrescentado o termo "Explique" como forma de trazer à discussão os elementos que configuraram a expressão "alguma coisa", na referida pergunta, de acordo com a compreensão dos próprios alunos.

As análises dessas respostas levaram a distribuir os resultados em duas categorias:

- Categoria A - alunos que perceberam na correção um aporte para as suas aprendizagens. De modo geral, foi possível compreender que:

- grande parte identificou na correção já feita uma possibilidade de realizar tarefas futuras sem erros, pois teria ali a possibilidade de consultar exercícios semelhantes para "tirar as dúvidas";

- um segundo grupo também atribuiu à correção já feita a função de referência de estudo para as provas.

- Categoria $B$ - alunos que, embora tenham dito que o dever corrigido servia para alguma coisa, essa "alguma coisa" não tinha relação direta com suas aprendizagens. Como exemplo dessa categoria, destacam-se as seguintes explicações dadas por alguns alunos: "Sim, para as professoras saberem se a nossa letra tá bonita". (M., $2^{\circ}$ ano) 
"Sim, para ficar feito". (L., $3^{\circ}$ ano)

"Sim, para guardar no armário". (A., do $3^{\circ}$ ano)

"Serve para os pais entender". (Y., do $4^{\circ}$ ano)

"Talvez, só se a questão cair na prova". (D., do $5^{\circ}$ ano)

Igualmente, chama a atenção uma parcela de $24 \%$ dos alunos que externaram questões consideráveis que dão visibilidade ao universo do pensamento infantil e que devem ser objeto de estudo para as professoras do segmento do ensino fundamental I. Apresentam-se, a seguir, algumas transcrições na íntegra, a fim de que a essência das falas infantis possa ser percebida com clareza.

"Não serve porque ele é guardado no armário". (R., do $2^{\circ}$ ano)

"Não serve porque fica guardado na mochila". (J., do $2^{\circ}$ ano)

"Não, porque não vai ter mais nada pra fazer". (G., do $2^{\circ}$ ano)

"Não, porque quando acabamos já vamos pra outro dever". (P., do $3^{\circ}$ ano)

"Eu acho que não serve, porque depois que a tia corrige a gente fecha o caderno e acabou". (A., do $4^{\circ}$ ano)

"Não, porque depois que nós terminamos, nós não podemos desenhar na folha seguinte, que é a branca". (R., do $5^{\circ}$ ano)

Essas respostas, sem dúvida, têm muito a dizer sobre a necessidade da "superação da dicotomia entre o processo e o produto que, muitas vezes, se verifica na atividade de ensino-aprendizagem" (VEIGA, 2011, p. 145). A compreensão de que uma tarefa corrigida "serve para alguma coisa", ou seja, para a aprendizagem, deveria ser o princípio da atividade, e não um fim em si mesma (Figura 1). 
FIGURA 1: llustração produzida por uma aluna de oito anos de idade, participante da pesquisa

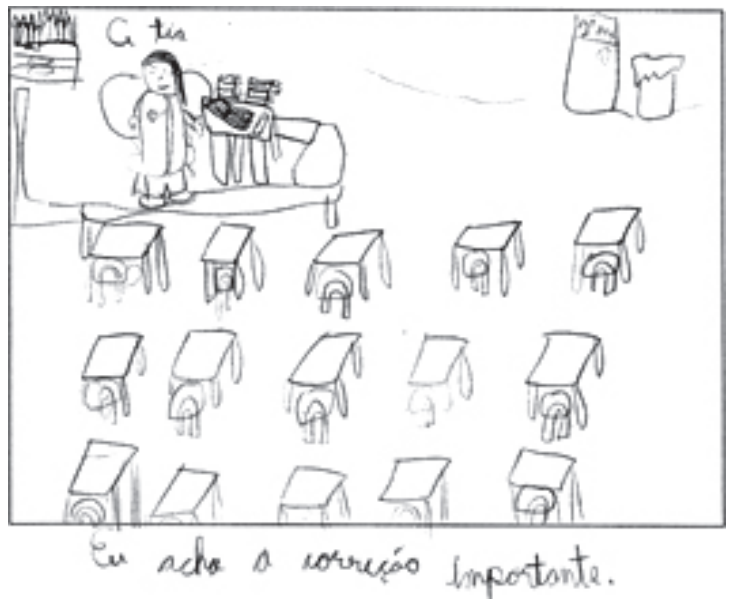

\section{CONCLUSÃO: POR QUÊ? COMO? PARA QUÊ?}

O inesperado surpreende-nos. É que nos instalamos de manei-

ra segura em nossas teorias e ideias, e estas não têm estrutura para acolher o novo. Entretanto, o novo brota sem parar. Não podemos jamais prever como se apresentará, mas devese esperar sua chegada, ou seja, o inesperado. E quando o inesperado se manifesta, é preciso ser capaz de rever nossas teorias e ideias, em vez de deixar o fato novo entrar à força na teoria incapaz de recebê-lo. (MORIN, 2011, p. 29)

Ao refletir, com Morin (2011), acerca do contexto da pesquisa, entende-se o inesperado como aquilo que surpreende a expectativa ou a crença anterior. Para quem trabalha em sala de aula do ensino fundamental, deparar-se com dados tão impactantes sobre as percepções dos alunos a respeito da prática das correções não é nada confortável. No mínimo, convida-nos a sair do lugar já sabido.

Como afirma Morin (2011), é necessário rever teorias para que elas possam dar conta de receber o novo. E foi com base nesse princípio que, do ponto de vista metodológico, procurou-se, ao longo de toda a pesquisa, desde o levantamento até a análise dos dados, saber escutar, perceber e evitar generalizações apressadas. 
No curso da pesquisa, buscou-se dar conta de realizar as análises de acordo com as questões que as orientaram. Porém, o inesperado também ocorreu. Durante as análises, percebeu-se a extensão dos materiais gerados e de sua riqueza em termos de potencial de exploração. Falas, comportamentos, gestos, intenções, procedimentos e registros foram as fontes que se apresentaram à nossa compreensão sobre as percepções das professoras.

Nesse cenário, os desenhos dos alunos suscitaram atenção, tamanha era sua expressividade. Essas produções tinham muito a informar sobre o entendimento que os alunos tinham da realidade, sobre como questionavam e interpretavam os fatos e os processos. Eça (2010, p. 157) advoga que, pelas características únicas de representações e de interpretações, "o desenho é uma ferramenta transversal de apropriação e manipulação da diversidade e o seu entendimento como um todo e não como a soma das suas partes".

Salas de aula vazias com cadernos empilhados sobre a mesa da professora, alunos comemorando ao saberem que acertaram as respostas, professora sentada e o aluno se aproximando da mesa para entregar o caderno num tamanho desproporcional, todas são representações carregadas de modos de "ver" e de "sentir" a correção, em muitas de suas expressões. Esses dados merecem estudos mais apurados. São questões latentes que são carregadas como o inesperado e que instigam a continuar pesquisando.

Quanto às considerações finais, pode-se dizer que analisar as percepções que professoras e alunos têm acerca dos objetivos que fundamentam a prática da correção dos exercícios no ensino fundamental I é tarefa complexa. Então, iniciam-se essas considerações com sustentação na didática, afirmando que:

\footnotetext{
A didática, tal como é concebida, deveria concernir ao mesmo registro: antecipar, prever tudo o que fosse possível, mas saber que o erro e a aproximação são a regra, que será preciso retificar o alvo constantemente. Nesse espírito, a regulação não é um momento específico da ação pedagógica, é um componente permanente dela. (PERRENOUD, 1999, p. 111)
} 
Nessa perspectiva, atribuir à prática da correção um valor de aporte ao ensino e à aprendizagem requer habilidade para conciliar propósitos formativos e métodos que os favoreçam. Para isso, é necessário adotar procedimentos que auxiliem as aprendizagens e, nesse sentido, o uso de feedbacks para superação das dificuldades.

No entanto, há que se reverem as fundamentações do ensino comprometido com as aprendizagens, se o que se pretende é corrigir como ato vinculado à avaliação formativa. Contudo, as interações nas salas de aula observadas e as correções realizadas nos cadernos dos alunos evidenciaram que ainda há uma submissão ao nível de suposições de quem observa. Existe uma distância entre as intenções e as práticas efetivas não satisfatórias, quando se pretende contribuir com as aprendizagens.

Estudo recente realizado por Gonçalves (2007) sobre a carreira das professoras do ensino fundamental I categorizou as fases dessa carreira tendo como referência a formação inicial. Aplicando-se os resultados desse estudo à pesquisa realizada, pelo tempo que possuem de magistério, as professoras colaboradoras podem ser situadas na quarta fase: a da serenidade. Segundo o autor, tal fase é marcada pela "satisfação de saber o que se está a fazer, acreditando-se que se está a fazer bem, confunde-se já, por vezes, com um certo conservadorismo" (GONÇALVES, 2007, p. 165), o que ressalta a relação entre formação inicial e formação continuada como fator fundamental para uma prática mais consciente e coerente com o propósito formativo da avaliação e da correção.

Portanto, se os espaços de discussão da escola forem aproveitados para a reflexão sobre o porquê, o como e o para quê da prática da correção de exercícios nos cadernos de alunos no ensino fundamental I, sem dúvida haverá ganhos expressivos. É nesse sentido que a formação continuada pode contribuir para dar visibilidade às práticas que acabam padronizadas.

Segundo os relatos das professoras entrevistadas, técnicas e procedimentos de correção não são objetos de discussão em grupo. Cada uma constrói o seu fazer a partir de suas 
próprias experiências. Como disse a professora A, "Na minha experiência, eu vejo que não discutimos sobre isso. A maneira como vocêfaz na sala de aula, é com você".

Seria interessante, por exemplo, apresentar numa "roda de conversa" o que se pretende ao perguntar para a turma, numa situação de correção, "quem errou essa?" ou "todo mundo fez?", ou ainda o que se quer fazer e o que se faz realmente. Como será que se sente quem errou? Por que tantos reagem "mentindo" para responder tais perguntas?

Lembrando os estudos de Vigotski (2004) sobre a educação dos sentimentos, a primeira ação educativa deveria ser a mudança daqueles estímulos com os quais está vinculada a reação. Nesse sentido, as correções e o uso dos cadernos seriam estimulantes às aprendizagens, podendo-se afirmar que, a partir do entendimento da prática da correção como processo avaliativo, há possibilidade de se estruturar o trabalho em sala de aula pensando em por que corrigir, como corrigir e para que corrigir.

Com essa proposta, compreende-se que observar, interagir, diagnosticar e intervir sejam ações pedagógicas a serem contempladas na prática da correção. Afinal, o aluno aprende o que é feito com ele, e não o que o mandam fazer. E o que são essas ações senão princípios amplos da avaliação formativa?

É importante voltar a ressaltar que a participação efetiva do aluno no seu processo de aprendizagem o torna sujeito ativo na produção de seu saber, considerando-se também que, para o aluno avançar em suas aprendizagens, a interação com o outro é de expressiva relevância.

Assim, numa perspectiva formativa, muito se tem a discutir sobre:

- a (in)eficácia das regulações;

- a otimização das avaliações com as intervenções;

- a qualidade dos feedbacks;

- os espaços de formação continuada como possibilidades de trocas, com vistas a uma coerência entre intenções e práticas construtivas.

Subsequente a essa discussão, é possível sim apontar métodos e técnicas congruentes com os objetivos de uma 
avaliação formativa, o que fundamenta o nosso propósito em seguir no aprofundamento de estudos sobre esse tema.

$\mathrm{O}$ inesperado nos invadiu de tal forma, que fez com que esta pesquisa fosse, para nós, como um ponto de partida para uma trajetória de reinvenções: reinvenção da prática, reinvenção de teorias, reinvenção do sentido do aprenderensinaraprender.

Assim, o diálogo da autora do desenho que segue (Figura 2) diz muito sobre a relevância da realização desse estudo.

FIGURA 2: Ilustração produzida por uma aluna de 10 anos de idade, participante da pesquisa

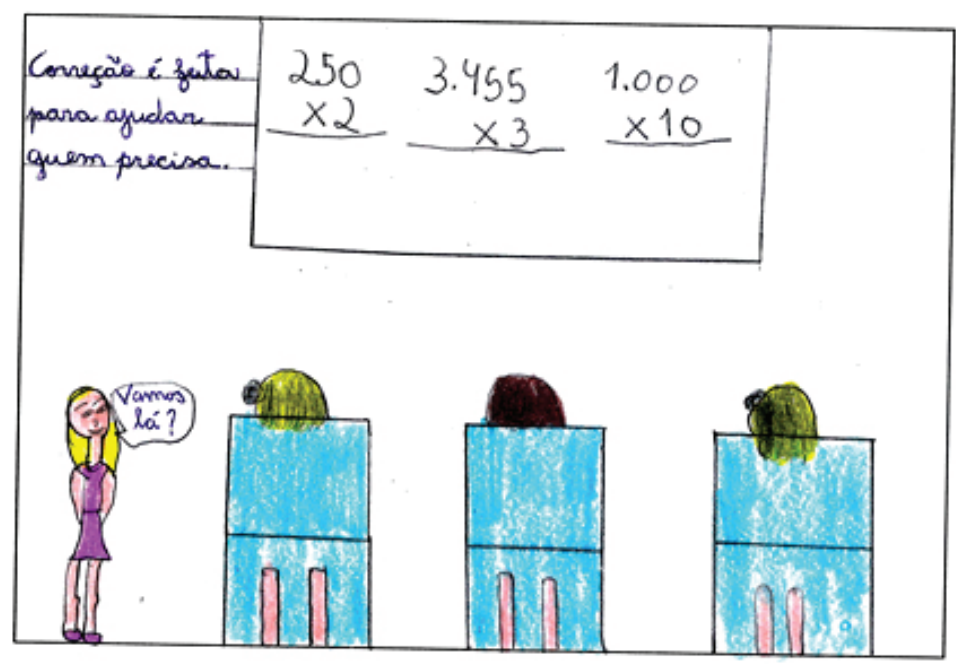

Finaliza-se, então, acrescentando: E quem é que não precisa de ajuda?

\section{REFERÊNCIAS}

ABRAHÃO, M. H. M. B. Professores e alunos: aprendizagens significativas em comunidades de prática educativa. Porto Alegre: EDIPUCRS, 2008.

AFONSO, A. J. Avaliação educacional: regulação e emancipação: para uma sociologia das políticas avaliativas contemporâneas. 4. ed. São Paulo: Cortez, 2009.

EÇA, T. T. Desígnios de desenho no contexto da cultura visual. Revista Educação \& Linguagem, v. 13, n. 22, p. 153-158, jul./dez. 2010.

FERNANDES, D. Para uma teoria da avaliação formativa. Revista Portuguesa de Educação, Universidade de Lisboa, Portugal, v. 19, n. 2, p. 21-50, 2006. 
GONÇALVES, J. A. M. A carreira das professoras do ensino primário. In: NÓVOA, A. Vida de professores. Porto: Porto, 2007.

MOREIRA, S. A. A prática da correção de exercícios no ensino fundamental I como processo avaliativo: Por quê? Como? Para quê? 2012. Dissertação (Mestrado) - Universidade Federal Fluminense, Niterói, 2012.

MORIN, E. Os sete saberes necessários à educação do futuro. 2. ed. São Paulo: Cortez; Brasília, DF: Unesco, 2011.

PERRENOUD, P. Avaliação. Da excelência à regulação das aprendizagens: entre duas lógicas. Porto Alegre: Artmed, 1999.

PIAGET, J. Psicologia e pedagogia. Tradução de Dirceu Accioly Lindoso e Rosa Maria Ribeiro da Silva. 10. ed. Rio de Janeiro: Forense Universitária, 2010.

RANGEL, M. Métodos de ensino para a aprendizagem e a dinamização das aulas. Campinas: Papirus, 2005.

VEIGA, I. P. A. (Org.). A prática pedagógica do professor de didática. Campinas: Papirus, 1989.

. Técnicas de ensino: por que não? 21. ed. Campinas: Papirus, 2011.

VIGOTSKI, L. S. Psicologia pedagógica. 2. ed. São Paulo: Martins Fontes, 2004. . A formação social da mente: o desenvolvimento dos processos superiores. São Paulo: Martins Fontes, 2007.

SIMONE ARAUJO MOREIRA

Mestre em Educação pela Universidade Federal Fluminense (UFF), Diretora Pedagógica do Colégio Salesiano Santa Rosa e Assessora Pedagógica do Colégio Lobo Torres, Niterói, Rio de Janeiro, Brasil simone.moreira@salesiano.br

\section{MARY RANGEL}

Professora Titular de Didática da Universidade Federal Fluminense (UFF) e Professora Titular na Área de Ensino-Aprendizagem da Universidade do Estado do Rio de Janeiro (UERJ), Rio de Janeiro, Rio de Janeiro, Brasil mary.rangel@lasalle.org.br 
